\title{
A Global Perspective on the Population Structure and Reproductive System of Phyllosticta citricarpa
}

\author{
E. Carstens, C. C. Linde, R. Slabbert, A. K. Miles, N. J. Donovan, H. Li, K. Zhang, M. M. Dewdney, \\ J. A. Rollins, C. Glienke, G. C. Schutte, P. H. Fourie, and A. McLeod
}

First, twelfth, and thirteenth authors: Department of Plant Pathology, Stellenbosch University, Private Bag X1, Matieland, 7601, South Africa; first, eleventh, and twelfth authors: Citrus Research International, PO Box 28, Nelspruit, 1200, South Africa; second author: Evolution, Ecology and Genetics, Research School of Biology, Building 116, Daley Rd, Australian National University, Canberra, ACT 2601, Australia; third author: Central Analytical Facilities, Stellenbosch University, Private Bag X1, Matieland, 7601, South Africa; fourth author: Centre for Plant Science, Queensland Alliance for Agricultural and Food Innovation, The University of Queensland, Brisbane, Queensland 4072, Australia; fifth author: New South Wales Department of Primary Industries, Elizabeth Macarthur Agricultural Institute, Private Bag 4008, Narellan, NSW 2567, Australia; sixth author: Biotechnology Institute, Zhejiang University, Hangzhou 310058, China; seventh and eighth authors: Citrus Research and Education Center, University of Florida, Lake Alfred 33850; ninth author: Department of Plant Pathology, University of Florida, Gainesville; and tenth author: Department of Genetics, Universidade Federal do Paraná, Curitiba, Paraná, Brazil.

Accepted for publication 20 January 2017.

\begin{abstract}
The citrus pathogen Phyllosticta citricarpa was first described 117 years ago in Australia; subsequently, from the summer rainfall citrus-growing regions in China, Africa, and South America; and, recently, the United States. Limited information is available on the pathogen's population structure, mode of reproduction, and introduction pathways, which were investigated by genotyping 383 isolates representing 12 populations from South Africa, the United States, Australia, China, and Brazil. Populations were genotyped using seven published and eight newly developed polymorphic simple-sequence repeat markers. The Chinese and Australian populations had the highest genetic diversities, whereas populations from Brazil, the United States, and South

Africa exhibited characteristics of founder populations. The U.S. population was clonal. Based on principal coordinate and minimum spanning network analyses, the Chinese populations were distinct from the other populations. Population differentiation and clustering analyses revealed high connectivity and possibly linked introduction pathways between South Africa, Australia, and Brazil. With the exception of the clonal U.S. populations that only contained one mating type, all the other populations contained both mating types in a ratio that did not deviate significantly from 1:1. Although most populations exhibited sexual reproduction, linkage disequilibrium analyses indicated that asexual reproduction is important in the pathogen's life cycle.
\end{abstract}

Phyllosticta citricarpa (McAlpine) Aa, which causes citrus black spot (CBS), is a good example of a recently introduced plant pathogen that constrains the global trade of a high-value fruit crop. Officially, CBS was first recorded and described from Australia on Valencia orange fruit in 1895 (Benson 1895). Soon after this report, McAlpine (1899) described the asexual stage of the fungus. The sexual, pseudothecial stage was later described by Kiely (1948). The first official record of the disease from citrus areas outside of Australia was from China (Lee 1920). Later, reports of the disease were published from Argentina (Marchionatto 1928), South Africa (Doidge 1929), and Brazil (Robbs et al. 1980). The most recent report was the introduction of the pathogen into Florida in the United States in 2010 (Schubert et al. 2012).

Today, global expansion of citrus production and the associated movement of propagation material have resulted in $P$. citricarpa being introduced into most of the major citrus-producing countries around the world that have a hot, wet, humid summer rainfall climate (Carstens et al. 2012; Paul et al. 2005; Yonow et al. 2013). The disease is absent and has never been reported from regions or countries with a Mediterranean, winter rainfall climate (Carstens et al. 2012; Paul et al. 2005; Yonow et al. 2013). Even within the same country, such as South Africa, Australia, and China, the disease is only present in the summer rainfall production areas (Carstens et al. 2012; Miles et al. 2008; Wang

Corresponding author: A. McLeod; E-mail address: adelem@sun.ac.za

*The $\boldsymbol{e}$-Xtra logo stands for "electronic extra" and indicates that two supplementary figures are published online

(C) 2017 The American Phytopathological Society et al. 2012). Although $P$. citricarpa has been reported as being present in New Zealand, which has an unsuitable climate for CBS (Paul et al. 2005; Yonow et al. 2013), this was an incorrect report due to the misidentification of $P$. capitalensis as $P$. citricarpa (Everett and ReesGeorge 2006). These two species are morphologically very similar but can be differentiated molecularly. $P$. capitalensis is an endophytic nonpathogenic species in citrus with a wide geographic distribution and host range (Baayen et al. 2002; Glienke et al. 2011; Stringari et al. 2009; Wikee et al. 2013a) and is of no phytosanitary concern in the world trade of fresh citrus fruit.

Despite the importance of CBS, little is known about the origin of $P$. citricarpa; however, it has been hypothesized that the pathogen is native to areas that are believed to be the primary center of origin of its host, genus Citrus. These include South- and Southeast Asia, specifically in the regions of Northeast India, south-eastward through the Malayan Archipelago to China and Japan, but also southward to and including Australia (Hynniewta et al. 2014; Malik et al. 2013; Scora 1975). The hypothesis for South- and Southeast Asia being the origin of $P$. citricarpa is supported by the diversity of Phyllosticta spp., with several new species recently being described from these regions, including $P$. citriasiana (Wulandari et al. 2009) and $P$. citrichinaensis (Wang et al. 2012) from citrus in China and $P$. citrimaxima from Thailand (Wikee et al. 2013b).

To manage a disease and prevent further incursions, it is important to understand the disease cycle of the pathogen, inoculum sources, and dissemination pathways. P. citricarpa produces two types of spores: namely, waterborne conidia (pycnidiospores) and aerially dispersed ascospores. Symptoms can develop on leaves, twigs, and fruit but symptoms on fruit are the most obvious. Waterborne, short-lived asexual pycnidiospores are produced in pycnidia on fruit, leaves, and 
twigs (Kiely 1948; Kotzé 1981, 2000; McOnie 1965; Spósito et al. 2007). Free water is required for the short-distance downward dispersal of pycnidiospores from symptomatic fruit within the tree (Kiely 1948; Spósito et al. 2007, 2008, 2011). Ascospores are sexually produced in pseudothecia that develop on leaf litter but never on fruit (Kiely 1948; Kotzé 1981, 2000). Pseudothecia mature over an extended period of time and require mild to warm temperatures and alternate wetting and drying (Fourie et al. 2013; Kiely 1948; Kotzé 1981). Ascospores are forcibly discharged from mature pseudothecia and are dispersed for distances up to $25 \mathrm{~m}$ (Spósito et al. 2007). Given the relatively short distance of dispersal of ascospores and pycnidiospores, latently infected propagation material is the most likely inoculum source that contributes toward the long-distance dissemination of the pathogen into new regions (Kiely 1948; Kotzé 1981, 2000; McOnie 1964a,b, 1965; Spósito et al. 2007, 2011; Wager 1953).

Recently, the occurrence of two opposite mating types (MAT 1-1-1 and MAT 1-2-1) has been reported in P. citricarpa populations, supporting the hypothesis that the fungus is heterothallic and will require mating between opposite mating types in order to produce ascospores (Amorim et al. 2016; Wang et al. 2013, 2016). Limited information is available on the mating type distribution of $P$. citricarpa worldwide, because the MAT loci were only characterized recently (Amorim et al. 2016; Wang et al. 2016). In Australia and Brazil, MAT genotyping of populations revealed an almost equal mating type distribution (Amorim et al. 2016; Wang et al. 2016; Zhang et al. 2015). However, in Florida in the United States, only one mating type has been identified, which implies an absence of sexual reproduction and, thus, ascospores (Wang et al. 2016).

Recent pathogen movement around the globe should be detectable in population genetic signals. For example, recent founder populations will be characterized by low genotype and allelic diversity (Dlugosch and Parker 2008; Linde et al. 2009). On the other hand, more established populations or populations with a long coevolutionary history with their host should display more allelic and genotype diversity. Information on population structure and diversity will also help to elucidate routes of pathogen introduction and migration. Furthermore, investigating the life history and evolutionary processes that shape pathogen populations in agriculture is important for understanding disease dynamics and to develop disease control and management strategies. For such studies, codominant neutral genetic markers are essential. Simple-sequence repeat (SSR) markers for $P$. citricarpa were developed recently from a published genome sequence of $P$. citricarpa and consist of seven polymorphic loci (Wang et al. 2016). These markers were used to genotype one population from Australia and several populations collected in different years from Florida. The markers identified two to four alleles per locus in the Australian population, and 11 multilocus genotypes (MLGs) among 24 Australian isolates. The Florida populations were all clonal, consisting of a single MLG (Wang et al. 2016; Zhang et al. 2015). Therefore, more informative markers are needed to examine the population structure and migration pathways of $P$. citricarpa.

In $P$. citricarpa, sequence data of individual loci have not been very useful for investigating the population structure due to low levels of polymorphisms. Wickert et al. (2012) used sequence data of the internal transcribed spacer (ITS)1-5.8S-ITS2 region to determine whether $P$. citricarpa populations from different orange varieties obtained from two geographic locations within Brazil were genetically differentiated. Their study revealed low genetic diversity in populations from different varieties and geographic areas. Similarly, a study from Australia showed high ITS sequence similarity among isolates of $P$. citricarpa (Miles et al. 2013). In a study by Zavala et al. (2014), genetic variation in P. citricarpa isolates from Florida was investigated relative to 18 global isolates (Brazil, South Africa, Zimbabwe, and Australia) using multilocus sequencing of four conserved loci (ITS, elongation factor 1- $\alpha$, actin, and glyceraldehyde-3-phosphate dehydrogenase). The analysis did not reveal any genetic variation among the investigated isolates.
On a global scale, almost no information is available on the population structure, routes of introduction, and putative origin of $P$. citricarpa. The first objective of this study was to develop additional SSR markers for population genetic studies using nextgeneration sequencing data of a South African P. citricarpa isolate. These SSR markers and published markers (Wang et al. 2016) were used to genotype $P$. citricarpa populations from South Africa, Brazil, Australia, the United States, and China in order to infer introduction routes, the possible center of origin of the pathogen, and founder populations. Finally, the mating type distribution, frequencies, and mode of reproduction were also investigated in the aforementioned populations. In combination with genotype diversities and linkage disequilibrium analyses, mating type distribution will provide valuable insights into the mode of reproduction of $P$. citricarpa. Information gained from this study will be valuable in decision making for disease management strategies to enhance global citrus production.

\section{MATERIALS AND METHODS}

Collection and isolation of $\boldsymbol{P}$. citricarpa isolates. $P$. citricarpa isolates from South Africa were sampled in 2011 and 2012 from a citrus orchard in each of the following provinces: Limpopo, Mpumalanga, North West, Eastern Cape, and KwaZulu-Natal. In 2011, a single orchard was sampled in Brazil, whereas three orchards were sampled in the United States and two orchards in China. In Australia, one orchard was sampled in 2010 and two orchards were sampled in 2011 (Table 1). For each orchard in South Africa, Brazil, and Australia, 40 to 50 randomly selected CBSsymptomatic fruit were collected. In the United States, 23 to 35 fruit were randomly sampled from each of the three orchards and, in China, 15 fruit were randomly selected from each of the two orchards. Fruit were surface sterilized with a $1.25 \%$ sodium hypochlorite solution or $70 \%$ ethanol for $5 \mathrm{~min}$ followed by rinsing in sterile water. Small fragments of the lesions obtained from fruit with hard spot symptoms were placed onto potato dextrose agar (PDA) (Biolab, Midrand, South Africa) containing chloramphenicol $(0.01 \%)$, and incubated for 10 to 14 days at $25^{\circ} \mathrm{C}$. One isolate was selected per fruit and a single spore culture was prepared for subsequent storage at $17^{\circ} \mathrm{C}$ in sterile distilled water and at $-85^{\circ} \mathrm{C}$ in $30 \%$ glycerol. Isolates from the United States were kept on dried sterile filter paper on desiccant at $-20^{\circ} \mathrm{C}$ for long-term storage.

Confirming the species identity of $\boldsymbol{P}$. citricarpa isolates. Due to $P$. citricarpa being morphologically very similar to $P$. capitalensis, the species identity of isolates was confirmed using morphological and molecular analyses. For morphological analyses, putative $P$. citricarpa single-spored isolates were transferred to oatmeal agar (OMA) (Biolab) plates and incubated at $25^{\circ} \mathrm{C}$ to differentiate $P$. citricarpa from other Phyllosticta spp. The plates were examined for the presence of a yellow halo around colonies after 7 days, because $P$. citricarpa is the only Phyllosticta sp. that produces this halo (Baayen et al. 2002; FAO 2014).

TABLE 1. Geographic origin, collection year, and host of Phyllosticta citricarpa populations analyzed in this study

\begin{tabular}{lllll}
\hline Country & Province, state, or county & Year & Citrus type & $N^{\mathrm{a}}$ \\
\hline Australia & Queensland 1 (Qld1) & 2011 & Lemon & 25 \\
& Queensland 2 (Qld2) & 2011 & Soft citrus & 29 \\
& New South Wales (NSW) & 2010 & Navels & 25 \\
Brazil & Sao Paulo & 2011 & Lemon & 24 \\
China & Jiangxi & 2011 & Soft citrus & 35 \\
\multirow{5}{*}{ South Africa } & Zhejiang & 2011 & Soft citrus & 23 \\
& Eastern Cape (SA-EC) & 2012 & Lemon & 20 \\
& KwaZulu-Natal (SA-KZN) & 2011 & Grapefruit & 30 \\
& Limpopo (SA-LIM) & 2011 & Valencia & 30 \\
& Mpumalanga (SA-MP) & 2011 & Valencia & 29 \\
\multirow{3}{*}{ Unites States } & North West (SA-NW) & 2012 & Lemon & 30 \\
& Collier County, Florida & 2011 & Valencia & 83 \\
\hline
\end{tabular}

a Number of isolates. 
Molecular identification was conducted using species-specific primers. DNA was isolated from 2-week-old mycelia growing on PDA plates. The fungal growth was scraped from the agar plates and lyophilized for DNA extraction using the Qiagen DNeasy Plant Mini Kit (Qiagen, Hilden, Germany). Species-specific primers (IDT, Coralville, IA) (Meyer et al. 2006; Peres et al. 2007) were used to amplify diagnostic fragments specific for $P$. citricarpa and $P$. capitalensis, following conditions described previously (Meyer et al. 2006; Peres et al. 2007). DNA of P. citricarpa (PPRI 9827) and P. capitalensis (PPRI 9065) (obtained from the National Collection of Fungi, Agricultural Research Council-Plant Protection Research Institute, Pretoria, South Africa) were included as positive species controls in the polymerase chain reaction (PCR) assays. PCR products were analyzed by electrophoresis at $100 \mathrm{~V}$ for $1 \mathrm{~h}$ in a $1 \%$ (wt/vol) agarose gel and visualized under UV light using a Genegenius Gel Documentation and Analysis System (Syngene, Cambridge, United Kingdom) after ethidium bromide staining.

Ion torrent genome sequencing and SSR marker development. Genomic DNA for sequencing with the Ion PGM (Life Technologies, Carlsbad, CA) system was extracted from a South African P. citricarpa isolate (STEU-7794) according to Goodwin et.al. (1992). Low-coverage whole-genome shotgun sequencing was performed using two Ion 318 chips and Ion sequencing V1 200-bp sequencing chemistry. These sequences (1,650 to $12,896 \mathrm{~kb})$ were assembled into 65 contigs using the Torrent Suite 2.2 and were sorted according to size using Galaxy (Blankenberg et al. 2010; Giardine et al. 2005; Goecks et al. 2010). Sequences containing at least four to six tandem repeat units of di- to hexa-nucleotides were mined for SSRs using BatchPrimer3, version 1 (Rozen and Skaletsky 1998). Fifty-seven primer pairs were designed using this online tool. These primer pairs were tested for amplification success and levels of polymorphism using a subset of 10 isolates, representing three countries (South Africa, Australia, and China). The PCR for amplification with the different primer pairs contained
20 ng of template DNA, 1× KAPA Readymix (KAPA Biosystems, Cape Town, South Africa), and $0.2 \mu \mathrm{M}$ each primer. Cycling was performed in a Veriti thermal cycler (Life Technologies) using the following conditions: $95^{\circ} \mathrm{C}$ for $5 \mathrm{~min}$; followed by 35 cycles of $95^{\circ} \mathrm{C}$ for $30 \mathrm{~s}, 52^{\circ} \mathrm{C}$ for $30 \mathrm{~s}$, and $72^{\circ} \mathrm{C}$ for $40 \mathrm{~s}$; followed by a final extension step at $72^{\circ} \mathrm{C}$ for $5 \mathrm{~min}$. The fragment lengths of PCR amplicons were analyzed on a 2100 Agilent Bioanalyzer (Agilent, Santa Clara, CA) using the DNA High Sensitivity Kit. Loci were considered polymorphic if two or more alleles were observed among the 10 evaluated isolates. Primers from the eight selected loci were labeled with FAM, PET, NED, and VIC fluorescent dyes and amplified in three multiplex reactions (Table 2). The PCR and cycling conditions were as described above. Electrophoresis was performed using the 3730XL Genetic Analyzer (Life Technologies). The SSR alleles were scored using Genemapper software (version 4; Life Technologies).

Seven published polymorphic loci (PC12, PC19, PC20, PC32, PC37, PC6, and PC7) (Wang et al. 2016) were also used to genotype the $P$. citricarpa populations. Primers from the selected loci were labeled with FAM, PET, NED, and VIC fluorescent dyes and amplified in two multiplex reactions (Table 2). The PCR for amplification with the different primer pairs contained $10 \mathrm{ng}$ of template DNA, $2 \times$ KAPA2G Fast Multiplex Mix (KAPA Biosystems), and $0.5 \mu \mathrm{M}$ each primer. Cycling was performed in a GeneAmp PCR System 9700 (Applied Biosystems) using the following conditions: $95^{\circ} \mathrm{C}$ for $5 \mathrm{~min}$; followed by 35 cycles of $94^{\circ} \mathrm{C}$ for $30 \mathrm{~s}, 57^{\circ} \mathrm{C}$ for $30 \mathrm{~s}$, and $72^{\circ} \mathrm{C}$ for $60 \mathrm{~s}$; followed by a final extension step at $72^{\circ} \mathrm{C}$ for $5 \mathrm{~min}$. Electrophoresis and SSR allele scoring were done as described above.

SSR data analyses. Selective neutrality of markers was evaluated with a Ewens-Watterson test in POPGENE (Yeh et al. 2000). Isolates with the same alleles at all loci were considered clones or MLGs. To determine the genotypic diversities in individual and regional populations, the number of MLGs, the expected number of MLGs after rarefaction (eMLG) to account for different sample sizes,

TABLE 2. Characteristics of 15 simple-sequence repeat markers used to genotype Phyllosticta citricarpa populations and the allele size ranges present in a collection of 383 isolates

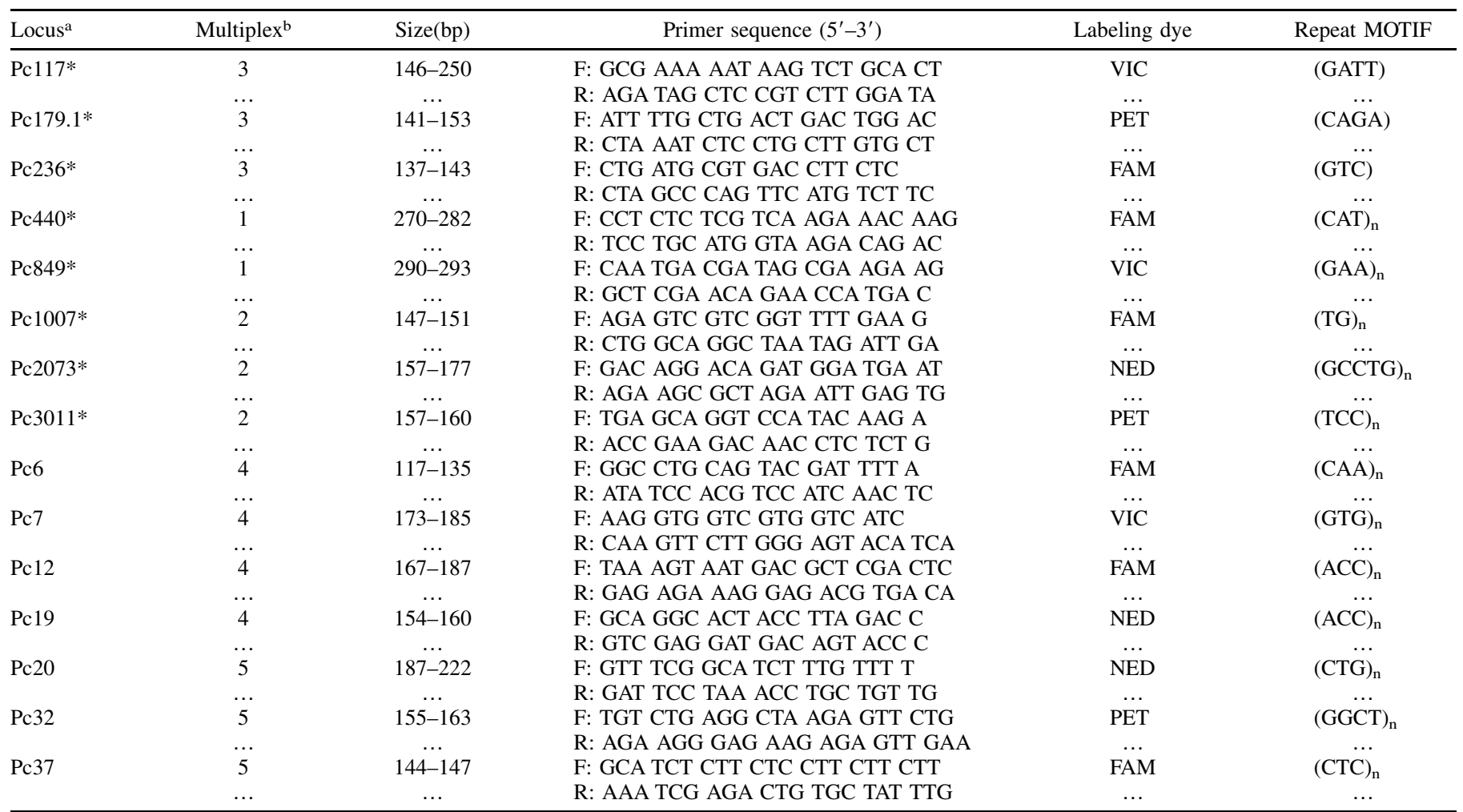

${ }^{a}$ Loci followed by an asterisk $(*)$ were developed in the current study, whereas the remaining loci were previously published by Wang et al. (2016).

${ }^{b}$ Multiplex reaction number. 
and the evenness index (E5) estimating the equitability in the distribution of the sampling units were determined in the $\mathrm{R}$ package poppr (Kamvar et al. 2014; R Core Team 2013). The equitability index $E 5$ varies from zero (no evenness) to one (all MLGs have equal abundance) (Grünwald et al. 2003; Shannon and Weaver 1949).

All allele-based population genetic analyses were conducted using a per-population clone-corrected dataset unless otherwise stated, because the inclusion of clonal haplotypes in the analysis can distort estimates of allelic diversity (Balloux et al. 2003). To determine the genetic diversity of populations, the following indices were calculated in GenAlEx, version 6.5 (Peakall and Smouse 2012): number of alleles, number of effective alleles, number of private alleles, number of polymorphic loci, and Nei's measure of gene diversity (Nei 1973). The values for Nei's gene diversity $\left(H_{e}\right)$ vary between zero and one. A zero value is an indication that there is no genetic diversity within the population (i.e., no allelic variation). The allele and allele richness for each population was determined using HP-RARE (Kalinowski 2005) to account for populations with different sample sizes. To assess whether the 15 SSR markers were able to discriminate between unique individuals (MLGs) in the complete dataset, a genotype accumulation curve was generated using the R package poppr (Kamvar et al. 2014; R Core Team 2013).

To estimate the distribution of variation within and among populations and regions, an analysis of molecular variance (AMOVA) was conducted. The statistical significance was tested using 999 permutations. Two identical MLGs from the U.S. population were included in the dataset to enable the performance of this analysis. To further assess genetic relatedness among populations, a principal coordinate analysis (PCoA) and a discriminant analysis of principal components (DAPC) were also conducted. The AMOVA and PCoA were performed in GenAlEx, version 6.5 (Peakall and Smouse 2012), whereas the DAPC was performed in the $\mathrm{R}$ package adegenet (Jombart 2008).

To visualize the relationships among MLGs in the 12 populations and to infer introduction pathways, SSR data were used to construct a minimum spanning network based on Bruvo's distance (Bruvo et al. 2004) using the R package poppr on nonclone-corrected data. The network was visualized using the package igraph (Csárdi and Nepusz 2006).

Mode of reproduction. MAT-specific primer pairs (Wang et al. 2016) were used to determine the mating type of 196 isolates that represented a clone-corrected dataset. The PCR contained $10 \mathrm{ng}$ of template DNA, $0.2 \mu \mathrm{M}$ each primer, $1 \times$ reaction buffer, $0.01 \mu \mathrm{l}$ of Taq DNA polymerase (Promega Corp., Madison, WI), $2 \mathrm{mM} \mathrm{MgCl}_{2}$, and $0.2 \mathrm{mM}$ each dNTP. Amplification of the MAT 1-1-1 allele was performed using the following conditions: denaturation step at $95^{\circ} \mathrm{C}$ for $5 \mathrm{~min}$; followed by 30 cycles at $95^{\circ} \mathrm{C}$ for $30 \mathrm{~s}, 55^{\circ} \mathrm{C}$ for $45 \mathrm{~s}$, and $72^{\circ} \mathrm{C}$ for $45 \mathrm{~s}$; followed by a final extension step at $72^{\circ} \mathrm{C}$ for $10 \mathrm{~min}$. The same conditions were followed for the MAT 1-2-1 allele, except that the annealing temperature was $60^{\circ} \mathrm{C}$. PCR products were analyzed by electrophoresis at $100 \mathrm{~V}$ for $1 \mathrm{~h}$ in a $1 \%$ (wt/vol) agarose gel and visualized under UV light using a Genegenius Gel Documentation and Analysis System (Syngene) after ethidium bromide staining. The primer pair for MAT 1-1-1 yielded a fragment of $630 \mathrm{bp}$ and the primer pair for MAT 1-2-1 yielded a fragment of $500 \mathrm{bp}$. A $\chi^{2}$ test (Fisher and Yates 1963) was used to determine whether the populations deviated from the null hypothesis of a 1:1 ratio of the mating type.

To infer the reproduction strategy (clonal or sexual) used by $P$. citricarpa, linkage disequilibrium analyses were performed on an SSR nonclone-corrected and clone-corrected dataset in the R package poppr by calculating the index of association $\left(I_{A}\right)$ and the standardized version of the $I_{A}\left(\bar{r}_{d}\right) . P$ values were obtained after 999 permutations (Agapow and Burt 2001). The $I_{A}$ and $\bar{r}_{d}$ indices provide an indication of the degree of association of alleles at different loci within and among populations compared with that observed in a permutated dataset. A value of zero is expected for physically unlinked loci under random mating (i.e., linkage equilibrium [null model]). Linkage disequilibrium among loci is indicated by a value significantly larger than zero, which is generated when no or infrequent sexual reproduction occurs.

\section{RESULTS}

Collection, isolation, and identification of $\boldsymbol{P}$. citricarpa isolates. In total, $383 P$. citricarpa isolates representing 12 populations from five countries were obtained for analyses (Table 1; Fig. 1). The species identity of all the isolates was confirmed to be $P$. citricarpa because all the isolates produced a 580-bp (Meyer et al. 2006) or 300-bp (Peres et al. 2007) amplicon with the P. citricarpaspecific PCR primers, and olivaceous-gray colonies with a yellow halo on OMA.

Ion torrent genome sequencing and SSR marker development. Only 8 of the 57 primer pairs that were evaluated on the subset of 10 isolates were polymorphic, and were used to genotype all the isolates. Sequence alignment of the newly developed SSR loci sequences with the Wang et al. (2016) loci showed that there were no sequence similarities between these loci.

SSR data analyses. In addition to the eight newly developed polymorphic SSRs, the seven published loci (Wang et al. 2016) were also polymorphic in the analyzed populations. The 15 polymorphic primer pairs revealed a total of 68 alleles across the 15 loci in 383 isolates, ranging from 2 to 18 alleles (Table 3 ). The markers were all selectively neutral according to the Ewens-Watterson test (data not shown). Two of the loci (Pc236 and Pc849) were polymorphic only in the Chinese populations. Loci Pc117 and Pc20 were the most polymorphic and identified 18 and 8 alleles in the 12 populations, respectively. On a regional scale, the populations from China contained the greatest number of alleles $(n=54)$ followed by Australia $(n=38)$ and South Africa $(n=35)$ (Table 3). Furthermore, when the data were corrected for sample size and rarefactioned to a sample size of 20 isolates, the private allelic richness was the highest in the two Chinese populations ( 0.37 and 0.28 ). Of all the other analyzed populations, one private allele was found only in one population from Australia (Queensland 1) and one population from South Africa (KwaZulu-Natal). None of the populations showed 100\% polymorphism for all 15 loci and none of the loci were polymorphic in the population from the United States. The populations from China $\left(H_{e}=\right.$ 0.324 , standard error $[\mathrm{SE}]=0.062)$ and Australia $\left(H_{e}=0.254, \mathrm{SE}=\right.$ $0.050)$ had the highest average gene diversities. The population from Brazil $\left(H_{e}=0.144, \mathrm{SE}=0.056\right)$ and the United States $(0)$ had the lowest gene diversity (Table 3 ).

Among the 383 isolates that were analyzed, 149 MLGs were identified using the 15 SSR markers (Table 4). This provided a better resolution of MLGs than when only the seven published SSR markers (45 MLGs) or the eight newly developed SSR markers (85 MLGs) were used. The genotype accumulation curve showed a linear increase as the number of loci increased, confirming the importance of using all 15 loci for discriminating MLGs (Fig. 2). However, the genotype accumulation curve did not reach a plateau, which indicated that additional loci would further improve discrimination among individuals. Nevertheless, given that the variation in number of MLGs identified decreased dramatically with the addition of the 15 th locus, and that at least the 83 isolates from the United States are likely to be true clones, the 15 loci used here were deemed sufficient to discriminate among most individuals in the 12 populations analyzed (Fig. 2).

The number of MLGs varied among populations, with the highest number $(n=60)$ identified in the Australian populations, followed by the South African populations $(n=54)$ and Chinese populations $(n=$ 43). Only one MLG was identified in the United States population, whereas Brazil contained six MLGs (Table 4). To account for different sample sizes, the eMLG values for each population and each country were determined. Thee MLG values also indicated that the Australian populations have the highest number of MLGs $(n=21.40)$, which agrees with the high genotypic diversity $(D=0.975)$. Based on 
the eMLG values, the highest numbers of MLGs in South Africa were found in the populations from North West $(n=14.75)$ and KwaZuluNatal $(n=14.09)$ and the lowest $(n=6)$ in the Eastern Cape province (Table 4). The $E 5$ values are an indication of the relative abundance of different genotypes in populations. The high evenness in populations from Australia $(E 5=0.782)$ and China $(E 5=0.870)$ indicated that genotypes are equally abundant in the populations and also are an indication of higher genotype diversity (Table 4). The lower genotype

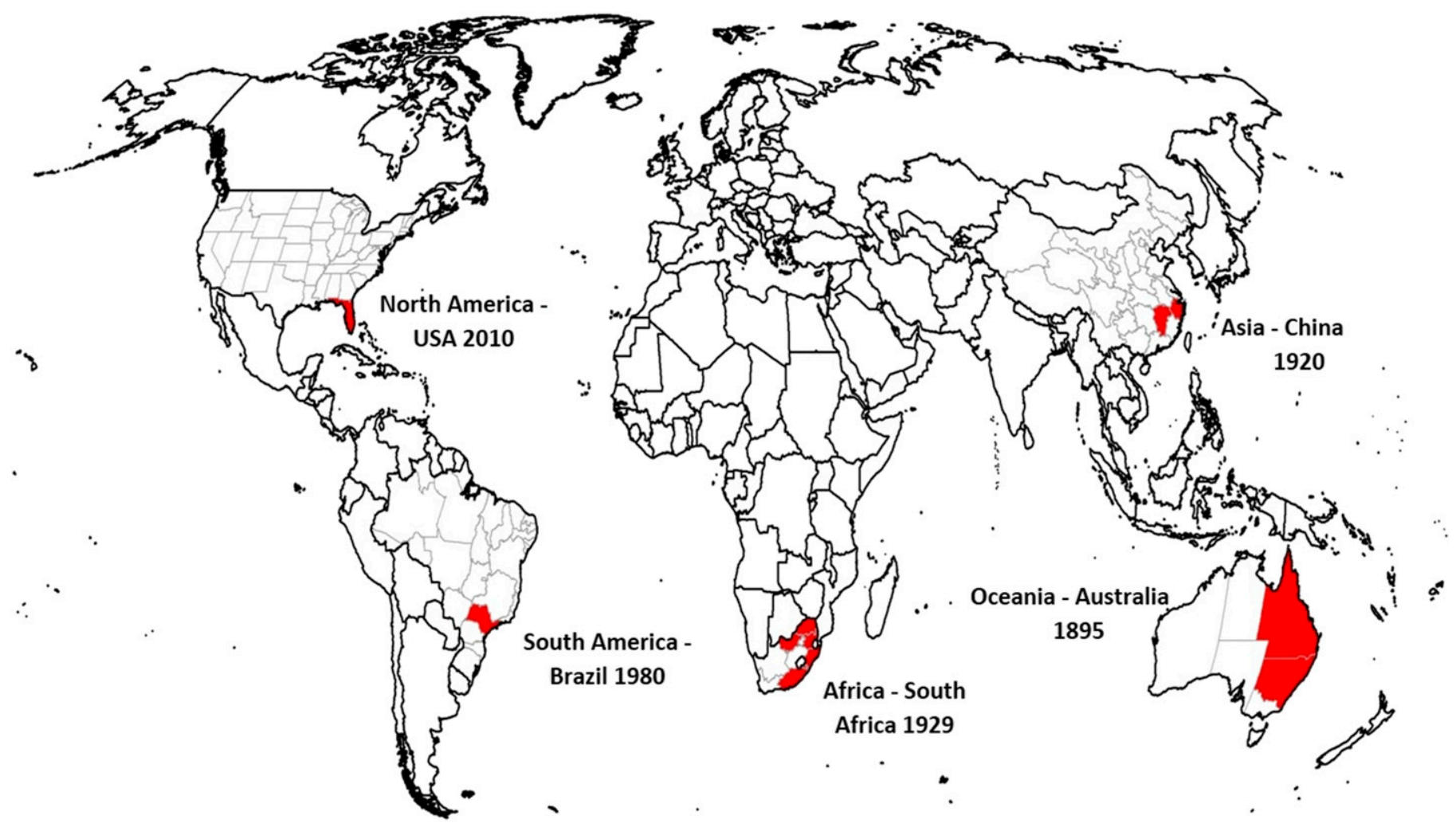

Fig. 1. Geographic distribution of the Phyllosticta citricarpa isolates indicating the five countries in which the isolates were collected. Dates indicated are those that are known as the earliest record of $P$. citricarpa.

TABLE 3. Number of alleles, private alleles, and gene diversity of 15 simple-sequence repeat loci in clone corrected Phyllosticta citricarpa populations from Australia, Brazil, China, South Africa, and the United States

\begin{tabular}{|c|c|c|c|c|c|c|c|c|c|c|c|c|c|c|c|c|c|c|}
\hline \multirow[b]{2}{*}{ Location $^{\mathrm{a}}$} & \multirow[b]{2}{*}{$N^{\mathrm{b}}$} & \multicolumn{16}{|c|}{ Number of alleles (private alleles) } & \multirow[b]{2}{*}{$H_{e}^{\mathrm{d}}$} \\
\hline & & $\begin{array}{c}\mathrm{Pc} \\
117\end{array}$ & $\begin{array}{c}\mathrm{Pc} \\
179.1\end{array}$ & $\begin{array}{c}\mathrm{Pc} \\
236\end{array}$ & $\begin{array}{c}\mathrm{Pc} \\
440\end{array}$ & $\begin{array}{c}\mathrm{Pc} \\
849\end{array}$ & $\begin{array}{c}\mathrm{Pc} \\
1007\end{array}$ & $\begin{array}{c}\mathrm{Pc} \\
2073\end{array}$ & $\begin{array}{c}\mathrm{Pc} \\
3011\end{array}$ & $\begin{array}{l}\mathrm{Pc} \\
12\end{array}$ & $\begin{array}{l}\mathrm{Pc} \\
19\end{array}$ & $\begin{array}{l}\mathrm{Pc} \\
20\end{array}$ & $\begin{array}{l}\mathrm{Pc} \\
32\end{array}$ & $\begin{array}{l}\mathrm{Pc} \\
37\end{array}$ & $\begin{array}{c}\mathrm{Pc} \\
6\end{array}$ & $\begin{array}{c}\mathrm{Pc} \\
7\end{array}$ & $N e^{\mathrm{c}}$ & \\
\hline NSW & 25 & 4 & 1 & 1 & 2 & 1 & 3 & 2 & 2 & 2 & 2 & 1 & 2 & 1 & 3 & 2 & 1.37 & 0.216 \\
\hline Queensland 1 & 25 & $4(2)$ & 2 & 1 & 3 & 1 & 2 & 1 & 2 & 3 & 2 & 1 & 2 & 2 & 3 & 1 & 1.48 & 0.243 \\
\hline Queensland 2 & 29 & 5 & 2 & 1 & 3 & 1 & 2 & 2 & 2 & 2 & 2 & 2 & 2 & 2 & 2 & 2 & 1.42 & 0.252 \\
\hline Total & 79 & $8(2)$ & 2 & 1 & 3 & 1 & 3 & 2 & 2 & 3 & 2 & 2 & 2 & 2 & 3 & 2 & 1.43 & 0.254 \\
\hline Total & 24 & 2 & 1 & 1 & 2 & 1 & 2 & 2 & 1 & 1 & 1 & 1 & 1 & 1 & 1 & 2 & 1.27 & 0.144 \\
\hline \multicolumn{19}{|l|}{ China } \\
\hline Jiangxi & 35 & $8(4)$ & 2 & $2(1)$ & 2 & 2 & 2 & 2 & 2 & $4(2)$ & $3(1)$ & $3(2)$ & 1 & 1 & $3(1)$ & 1 & 1.60 & 0.309 \\
\hline Zhejiang & 23 & $10(2)$ & 2 & 2 & $3(1)$ & 2 & 3 & 1 & 2 & $2(1)$ & 1 & $5(4)$ & 1 & 1 & 2 & $2(1)$ & 1.53 & 0.213 \\
\hline Total & 58 & $15(6)$ & 2 & $3(1)$ & $3(1)$ & 2 & 3 & 2 & 2 & $5(3)$ & $3(1)$ & $7(6)$ & 1 & 1 & $3(1)$ & $2(1)$ & 1.79 & 0.324 \\
\hline \multicolumn{19}{|l|}{ South Africa } \\
\hline EC & 20 & 1 & 1 & 1 & 2 & 1 & 1 & 2 & 2 & 1 & 1 & 1 & 1 & 1 & 2 & 2 & 1.17 & 0.107 \\
\hline \multicolumn{19}{|l|}{ United States } \\
\hline Collier Co., FL & 83 & 1 & 1 & 1 & 1 & 1 & 1 & 1 & 1 & 1 & 1 & 1 & 1 & 1 & 1 & 1 & 1.00 & 0 \\
\hline Total & 83 & 1 & 1 & 1 & 1 & 1 & 1 & 1 & 1 & 1 & 1 & 1 & 1 & 1 & 1 & 1 & 1.00 & 0 \\
\hline Total & 383 & 18 & 3 & 3 & 5 & 2 & 3 & 3 & 2 & 6 & 3 & 8 & 2 & 2 & 4 & 4 & 1.37 & 0.184 \\
\hline
\end{tabular}

${ }^{a}$ Country, state, province, county. NSW = New South Wales, EC = Eastern Cape, KZN = KwaZulu-Natal, LIM = Limpopo, MP = Mpumalanga, and NW = North West.

b Number of isolates.

${ }^{\mathrm{c}} \mathrm{Ne}=$ effective population size.

d Nei's gene diversity (Nei 1973). 
evenness in populations from Brazil $(E 5=0.694)$ and South Africa $(E 5=0.626)$ are an indication that these populations are dominated by a smaller number of genotypes (clones).

Various MLGs were shared among populations from South Africa, Australia, Brazil, and the United States but none were shared with populations from China. The U.S. MLG was shared with Australia (populations from Queensland 1 and New South Wales) and South Africa (populations from Mpumalanga, KwaZulu-Natal, and North West) but not with Brazil or China. The population from Brazil shared MLGs with all three populations from Australia and all five populations from South Africa. The South African population from the Eastern Cape only shared MLGs with the Queensland 2 population from Australia. The South African population from the Limpopo province shared MLGs with the Queensland 2 and the New South Wales populations from Australia. The North West population shared MLGs with the Queensland 1 and New South Wales populations from Australia. The South African populations from the Mpumalanga and KwaZulu-Natal provinces shared MLGs with all three Australian populations (data not shown).

The AMOVA analyses comparing the 12 populations from the five countries showed that $53 \%$ of the total variance was distributed among countries. A relatively low level of variance $(7 \%)$ was distributed among the 12 populations, whereas a higher proportion of the variation $(41 \%)$ was distributed within populations. There was significant $(P=0.001)$ genetic variation among countries $(P h i R T=0.528)$ and within populations $(P h i P T=0.593)$. The genetic variation among populations was low $(P h i P R=0.138)$ (Table 5).

Pairwise $P h i P T$ values indicated that the genetic differentiation varied significantly among some but not all countries (Table 6). The U.S. population was not significantly differentiated from the Australian $(P=0.438)$, South African $(P=0.481)$, or Brazilian $(P=0.365)$ populations. The South African population was not significantly differentiated from that of Brazil $(P=0.318)$ but was differentiated from the Australian population $(P=0.001)$. The Chinese population was significantly $(P=0.001)$ differentiated from all other populations (PhiPT $=0.694$ to 0.700$)$.

TABLE 4. Summary of genotypic diversity indices for 12 populations of Phyllosticta citricarpa from Australia, Brazil, China, South Africa, and the United States $^{\mathrm{a}}$

\begin{tabular}{|c|c|c|c|c|c|c|}
\hline \multirow[b]{2}{*}{ Location $^{\mathrm{b}}$} & \multicolumn{3}{|c|}{ Number of } & \multirow[b]{2}{*}{ SE } & \multirow[b]{2}{*}{ E5 } & \multirow[b]{2}{*}{$D$} \\
\hline & Isolates & MLGs & eMLG & & & \\
\hline \multicolumn{7}{|l|}{ Australia } \\
\hline Queensland 1 & 25 & 23 & 18.73 & 0.654 & 0.961 & 0.954 \\
\hline Queensland 2 & 29 & 25 & 17.82 & 0.965 & 0.883 & 0.951 \\
\hline NSW & 25 & 23 & 18.73 & 0.654 & 0.961 & 0.954 \\
\hline Total & 79 & 60 & 21.40 & 1.39 & 0.782 & 0.975 \\
\hline \multicolumn{7}{|l|}{ Brazil } \\
\hline Sao Paulo & 24 & 6 & 5.64 & 0.530 & 0.694 & 0.684 \\
\hline Total & 24 & 6 & 6.00 & 0.530 & 0.694 & 0.684 \\
\hline \multicolumn{7}{|l|}{ China } \\
\hline Jiangxi & 35 & 24 & 15.84 & 1.289 & 0.859 & 0.945 \\
\hline Zhejiang & 23 & 20 & 17.64 & 0.662 & 0.904 & 0.941 \\
\hline Total & 58 & 43 & 20.90 & 1.38 & 0.870 & 0.970 \\
\hline \multicolumn{7}{|l|}{ South Africa } \\
\hline KZN & 30 & 19 & 14.09 & 1.249 & 0.789 & 0.920 \\
\hline LIM & 30 & 15 & 11.70 & 1.183 & 0.712 & 0.880 \\
\hline MP & 29 & 14 & 11.38 & 1.101 & 0.746 & 0.880 \\
\hline NW & 30 & 20 & 14.75 & 1.237 & 0.820 & 0.929 \\
\hline $\mathrm{EC}$ & 20 & 6 & 6.00 & 0.000 & 0.735 & 0.710 \\
\hline Total & 139 & 54 & 16.90 & 1.930 & 0.626 & 0.952 \\
\hline \multicolumn{7}{|l|}{ United States } \\
\hline Collier Co., FL & 83 & 1 & 1.00 & 0.000 & $\ldots$ & 0 \\
\hline Total & 83 & 1 & 1.00 & 0.000 & & 0 \\
\hline Total & 383 & 149 & 14.59 & 1.917 & 0.256 & 0.930 \\
\hline
\end{tabular}

a MLGs $=$ multilocus genotypes, $\mathrm{eMLG}=$ expected MLGs after rarefaction, $\mathrm{SE}=$ standard error based on eMLG, $E 5=$ evenness, and $D=$ genotypic diversity.

b Country, state, province or county. NSW $=$ New South Wales, EC $=$ Eastern Cape, $\mathrm{KZN}=$ KwaZulu-Natal, LIM = Limpopo, MP = Mpumalanga, and $\mathrm{NW}=$ North West.
A PCoA clearly divided the isolates into two groups (Fig. 3). The first group included the populations from China and the second group included populations from South Africa, Brazil, the United States, and Australia.

The minimum spanning network revealed that the MLGs from China are distinct from all the other populations analyzed and have a separate evolutionary history (Fig. 4). The MLGs from South Africa, Australia, and Brazil were distributed all across the network but distant from the Chinese MLGs. The DAPC also divided the isolates from the 12 populations into two groups, with the isolates from China clearly separated from those from South Africa, Brazil, the United States, and Australia (Supplementary Fig. S1). A DAPC to assess the relationship between the populations in the main group (Australia, Brazil, South Africa, and the United States) also showed that there is no significant differentiation between the populations from these four countries (Supplementary Fig. S2).

Mode of reproduction. A positive PCR amplification with either one of the MAT primer pairs was achieved for all isolates analyzed. In all of the populations from Australia, Brazil, China, and South Africa, the mating type frequencies did not deviate significantly from a $1: 1$ ratio $\left(\chi^{2}=1.14\right.$ to $\left.2.26 ; P>0.1\right)$ based on $\chi^{2}$ analyses (Table 7$)$. In contrast, all the isolates obtained from the United States contained only a single MAT locus (MAT 1-2).

Linkage disequilibrium analyses were performed to infer the reproductive strategy. For the nonclone-corrected dataset, the $I_{A}$ and $\bar{r}_{d}$ indices in the association tests differed significantly from zero in 5 (Queensland 1, Brazil, China [Jiangxi], KwaZulu-Natal, and Limpopo) of the 12 populations (Table 8). This is an indication of linkage among loci and, thus, a deviation from random mating. In the

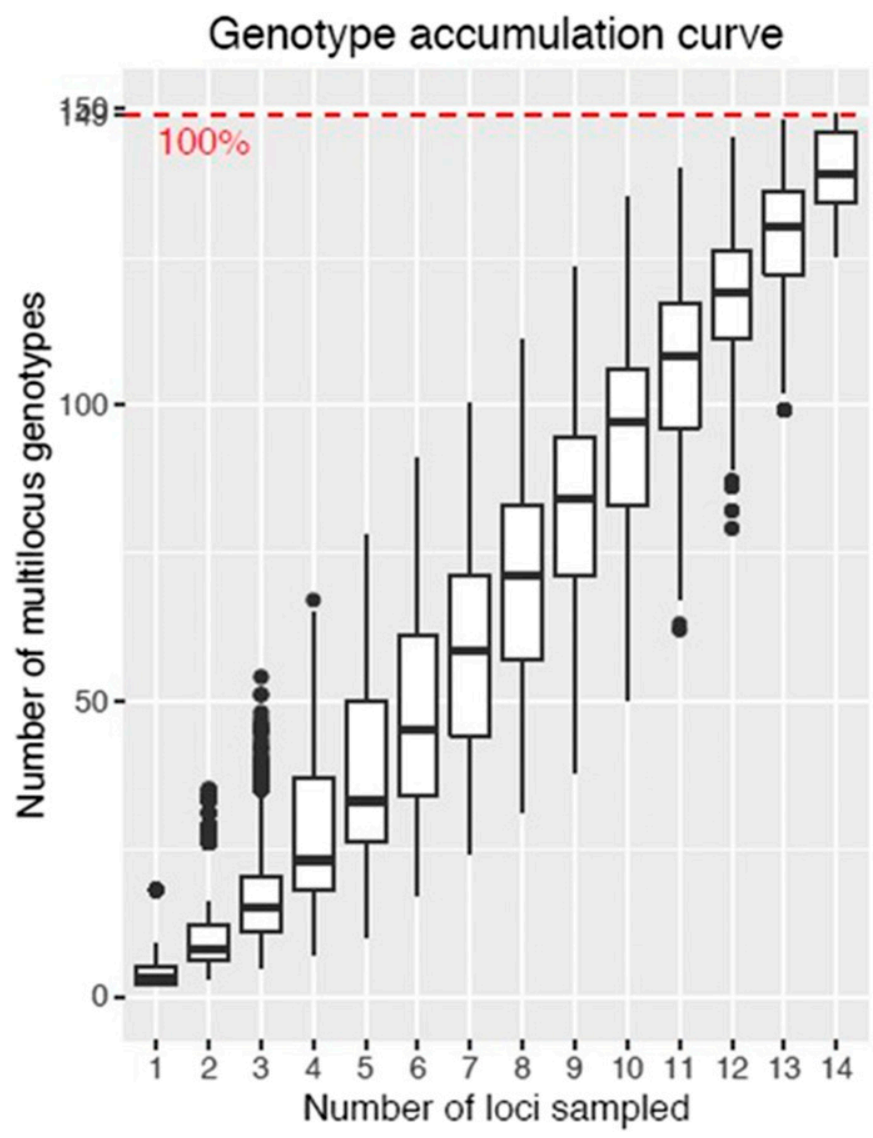

Fig. 2. Genotype accumulation curve for 15 microsatellite loci in 12 Phyllosticta citricarpa populations. Numbers of observed multilocus genotypes (MLGs) are denoted by the vertical axis, from 0 to the observed 149 MLGs (dashed line) in the $P$. citricarpa populations. Numbers of loci that were randomly sampled without replacement are denoted on the horizontal axis. Boxplots each contain 1,000 random samples representing different possible combinations of $n$ loci. MLG resolution of $100 \%$ is indicated by the horizontal dashed line. 
other seven populations, the hypothesis of random mating could not be rejected. For the clone-corrected dataset, the association tests differed significantly from zero in only 3 (Queensland 1, Brazil, and China [Jiangxi]) of the 12 populations (Table 8). Significant linkage disequilibrium may be achieved by no or infrequent sexual reproduction.

\section{DISCUSSION}

In this study, using a population genetics approach, a worldwide collection of $P$. citricarpa isolates originating from five continents was analyzed. The study revealed some novel and important aspects regarding the relatedness of populations from different continents, possible pathways of introduction, and the reproductive system of $P$. citricarpa. China and Australia were shown to have had a longer evolutionary history of $P$. citricarpa compared to South Africa, Brazil, and the United States. This is in agreement with the documented history of first reports of the pathogen in these countries. The U.S. population was confirmed to be clonal, using eight newly developed SSR markers. Populations from South Africa, Australia, Brazil, and the United States shared some MLGs, which is indicative of long-distance human-mediated dispersal. Investigations into the reproductive system of the pathogen showed that all populations, except the U.S. population, contained both MAT, and that asexual reproduction may play a more important role in the epidemiology of

TABLE 5. Analysis of molecular variance (AMOVA) for Phyllosticta citricarpa populations in five countries using 15 simple-sequence repeat loci ${ }^{a}$

\begin{tabular}{lrrrcc}
\hline Source & & & \multicolumn{3}{c}{ AMOVA } \\
\hline Among countries & 4 & \multicolumn{1}{c}{ SS } & Variation (\%) & statistics & $P$ \\
Among populations & 7 & 46.994 & 53 & $P h i R T=0.528$ & 0.001 \\
Within populations & 185 & 318.711 & 41 & $P h i P R=0.138$ & 0.001 \\
Total & 196 & 684.964 & 100 & PhiPT $=0.593$ & 0.001 \\
\end{tabular}

a Abbreviations: $\mathrm{df}=$ degrees of freedom and $\mathrm{SS}=$ sum of squares.

TABLE 6. Estimates of pairwise PhiPT values (below the diagonal) averaged over 15 microsatellite loci of Phyllosticta citricarpa populations in five countries (Australia, Brazil, China, South Africa, and the United States) ${ }^{\mathrm{a}}$

\begin{tabular}{lccccc}
\hline & Australia & Brazil & China & South Africa & United States \\
\hline Australia & $\ldots$ & 0.011 & 0.001 & 0.001 & 0.438 \\
Brazil & 0.097 & $\ldots$ & 0.001 & 0.318 & 0.365 \\
China & 0.649 & 0.659 & $\ldots$ & 0.001 & 0.001 \\
South Africa & 0.165 & 0.013 & 0.700 & $\ldots$ & 0.481 \\
United States & 0.000 & 0.013 & 0.674 & 0.000 & $\ldots$ \\
\hline
\end{tabular}

a Significance values indicated above the diagonal. the disease than previously thought. Population genetic inferences were strengthened by the development of eight new polymorphic SSR markers, which were used in combination with seven previously published SSRs (Wang et al. 2016). Some of the new markers (loci Pc117 and Pc440) were highly polymorphic and identified 5 to 18 alleles in the 12 analyzed populations that allowed for a better resolution of MLGs, as was evident from the genotype accumulation curve.

Knowledge of the origin of Citrus spp. (the host of P. citricarpa) could aid in the development of hypotheses on the origin of the pathogen. However, the origin, domestication, distribution, and botanical classification or taxonomy of edible or true Citrus spp. are characterized by a history of controversy and interesting folklore. Yet, it is accepted that Citrus most likely originated from certain parts of Southeast Asia, possibly China, India, and the Malay Archipelago (Gmitter and Hu 1990). More recently, Liu et al. (2012) and Carbonell-Caballero et al. (2015) considered Australia, New Caledonia, and New Guinea to be the center of origin. In the current study, $P$. citricarpa populations were sampled from some of the regions hypothesized as being the center of origin of Citrus. Two of the major citrus production areas in China were sampled, which included the Jiangxi area, where citrus has been produced since the Xia dynasty (21st to 17th century B.C.) (AQSIQ 2014). However, in Australia, only commercial citrus production areas in Queensland and New South Wales were sampled but not regions close to New Caledonia and New Guinea. Therefore, future analyses of populations from New Caledonia and New Guinea as well as the Malay Archipelago will be instrumental in better understanding the origin of $P$. citricarpa.

Combined with the known native distribution of Citrus hosts in China and Australia, the high levels of gene and genotypic diversities of $P$. citricarpa populations identified in China and Australia, as well as the presence of more private alleles in these populations, indicate that the pathogen has had a long coevolutionary history with its host in these countries. It is known that allele diversity is affected by the length of time that a specific population occurs in a specific area, with older populations having a higher level of genetic diversity, with more alleles and also more private alleles (Linde et al. 2009). This finding is also consistent with a coevolutionary relationship between the pathogen on its wild host.

The low genetic diversity of the five South African P. citricarpa populations and the population from Brazil is an indication of these populations being founder populations that have undergone genetic drift. Further support for this hypothesis is gained from low numbers of private alleles in the South African populations compared with populations from Australia and China, and the lack of private alleles in the Brazilian population. In Brazil, the low

Principal Coordinates (PCoA)

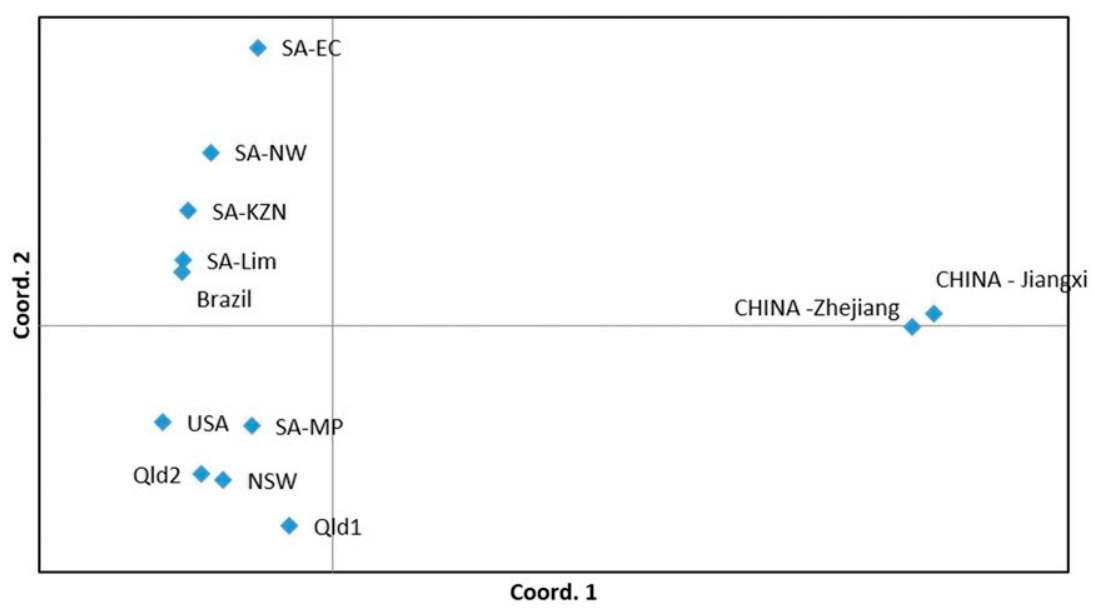

Fig. 3. Principal coordinate analysis (PCOA) for 12 Phyllosticta citricarpa populations collected in five different countries. 
genetic diversity can be attributed to a more recent introduction of P. citricarpa (Robbs et al. 1980). Similarly, the low genetic diversity in the South African populations may also be attributed to a relatively recent introduction (Doidge 1929).

In South Africa, the population from the KwaZulu-Natal province had the highest level of gene and genotypic diversity, whereas the Eastern Cape population had the lowest. This correlates with the history of CBS in South Africa. The recorded first discovery of CBS in South Africa was in 1929 in the humid coastal regions of the KwaZulu-Natal province but the disease only became severe in 1940. During surveys in 1946, the disease was also found in the North West, Limpopo, and Mpumalanga provinces (previously known as the Western Transvaal, Northern Transvaal, and Eastern Transvaal, respectively) (Wager 1952). The disease was first discovered in the Eastern Cape province in the 1970s (C. Kellerman, personal communication).

The $P$. citricarpa populations from the five continents differed in their connectivity and differentiation from each other, which provided clues as to possible introduction pathways. PCoA, DAPC, and a minimum spanning network based on genetic distances between MLGs revealed that there is little connectivity between the Chinese populations and the populations from the other countries (South Africa, Brazil, Australia, and the United States). This was also supported by the pairwise PhiPT comparisons. Population differentiation and clustering analyses showed that there are high levels of connectivity between South Africa, Australia, and Brazil, as well as between South Africa, Australia, and the United States. No connectivity was evident between the U.S. population and the population from Brazil. The high levels of connectivity among the P. citricarpa populations in South Africa, Australia, and Brazil is most likely due to exchanges of plant material and the associated $P$. citricarpa genotypes, either between these countries directly or between unsampled populations that share the same $P$. citricarpa populations. Sharing of plant material and possibly P. citricarpa may date back to the establishment of the citrus industries in these countries. The recorded history of the South African citrus industry goes back as far as 1654, when the first trees were brought from the Island of St. Helena, a stopover for ships from the East (Scora 1975). Additional records prior to the 1900s indicated that citrus trees were also brought to South Africa from Brazil (in 1850) and India (Allwright 1957; Powell 1930). The commercial citrus industry in Australia was established using trees imported in 1788 from the Cape of Good Hope (South Africa) and Rio de Janeiro, Brazil (Scora 1975). The citrus industry in Brazil was founded with trees brought from Europe in 1540 by the Portuguese explorers (http:// irrec.ifas.ufl.edu) (Navarro de Andrade 1933).

\section{POPULATION

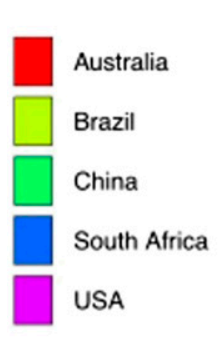

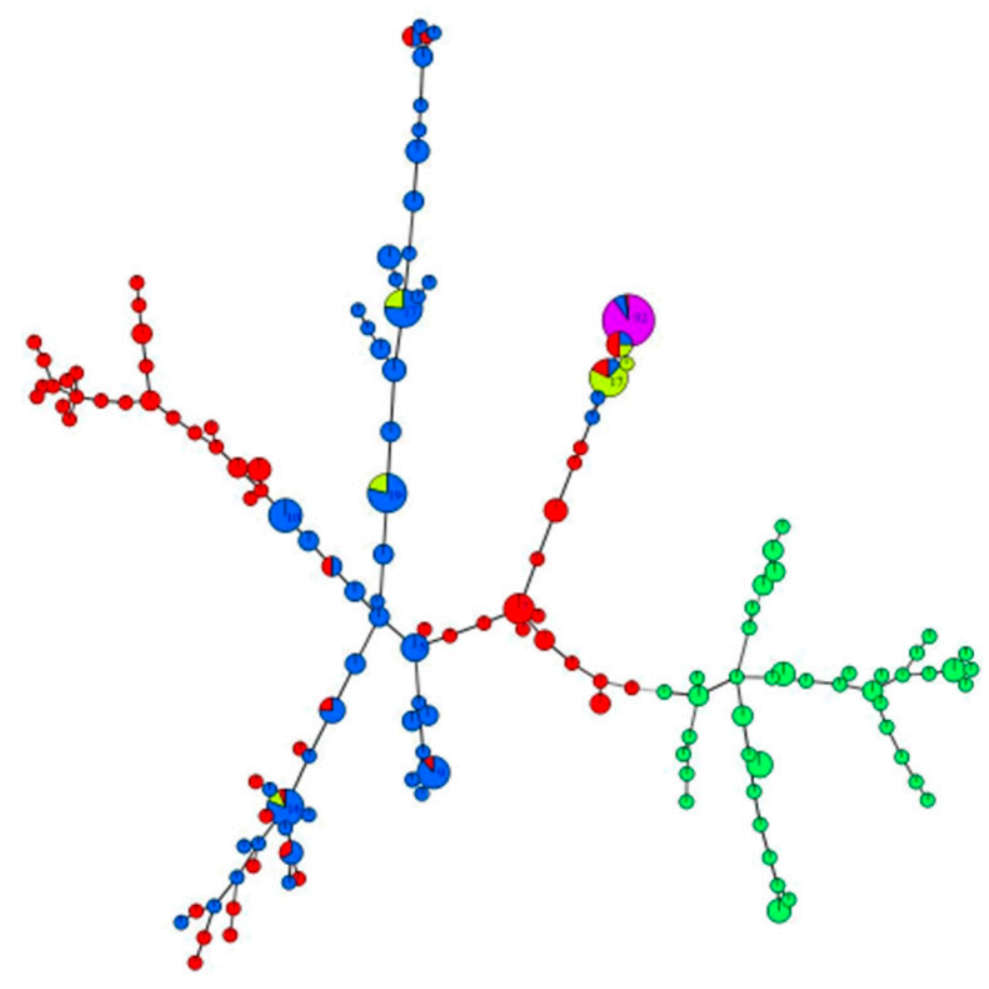

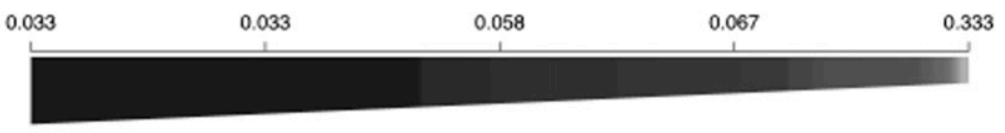

DISTANCE

Fig. 4. Minimum spanning network based on Bruvo genetic distances. In total, 149 multilocus genotypes were observed in Phyllosticta citricarpa populations from five countries. Node colors represent population membership proportional to the pie size. Node sizes are relatively scaled to $\log _{1.75} n$, where $n$ is the number of samples in the nodes to reduce node overlap. Edges (lines) represent minimum genetic distance between individuals. 
The mating type analysis and genotyping showed that only a single clonal mating type (MAT 1-2-1) was present in the U.S. population, which suggests a human introduction, a founder effect, and subsequent asexual reproduction of the pathogen in Florida, as was also reported by Wang et al. (2016). The finding of only one mating type in the U.S. population will result in atypical disease cycles compared with other countries. In this population, the

TABLE 7. Mating-type (MAT) composition and $\chi^{2}$ testing for expected 1:1 MAT ratios in clone-corrected Phyllosticta citricarpa populations from five countries

\begin{tabular}{|c|c|c|c|c|c|c|}
\hline \multirow[b]{2}{*}{ Location $^{\mathrm{a}}$} & \multirow[b]{2}{*}{ Populations } & \multicolumn{2}{|c|}{$\begin{array}{l}\text { Number } \\
\text { of MAT } \\
\text { isolates }\end{array}$} & \multirow[b]{2}{*}{ MLGs } & \multicolumn{2}{|c|}{ Value } \\
\hline & & $\overline{\mathrm{A} 1}$ & $\bar{A} 2$ & & $\chi^{2}$ & $P$ \\
\hline \multicolumn{7}{|l|}{ Australia } \\
\hline Queensland 1 & 1 & 12 & 11 & 23 & 0.04 & 0.80 \\
\hline Queensland 2 & 1 & 14 & 11 & 25 & 0.36 & 0.50 \\
\hline New South Wales & 1 & 14 & 9 & 23 & 1.09 & 0.30 \\
\hline Total & 3 & 40 & 31 & 71 & 1.14 & 0.30 \\
\hline \multicolumn{7}{|l|}{ Brazil } \\
\hline Sao Paulo/Parana & 1 & 4 & 2 & 6 & 0.67 & 0.50 \\
\hline \multicolumn{7}{|l|}{ China } \\
\hline Jiangxi & 1 & 14 & 10 & 24 & 0.67 & 0.50 \\
\hline Zhejiang & 1 & 13 & 7 & 20 & 1.80 & 0.20 \\
\hline Total & 2 & 27 & 17 & 44 & 2.26 & 0.10 \\
\hline \multicolumn{7}{|l|}{ South Africa } \\
\hline Eastern Cape & 1 & 3 & 3 & 6 & $\ldots$ & $\ldots$ \\
\hline KwaZulu-Natal & 1 & 12 & 7 & 19 & 1.32 & 0.30 \\
\hline Limpopo & 1 & 5 & 10 & 15 & 1.67 & 0.20 \\
\hline Mpumalanga & 1 & 6 & 8 & 14 & 0.29 & 0.70 \\
\hline North West & 1 & 6 & 14 & 20 & 3.20 & 0.10 \\
\hline Total & 5 & 32 & 42 & 74 & 1.35 & 0.30 \\
\hline \multicolumn{7}{|l|}{ United States } \\
\hline Collier Co., FL & 1 & 0 & 1 & 1 & $\ldots$ & $\ldots$ \\
\hline
\end{tabular}

${ }^{a}$ Country, province, state or county.

b Total number of multilocus genotypes (MLGs) per population in clonecorrected P. citricarpa populations from Australia, Brazil, China, South Africa, and the United States. primary inoculum is pycnidiospores; whereas, in populations from other continents, the primary inoculum is sexually produced ascospores. Asexual overwintering of the pathogen might occur endophytically as latent infections in leaves or twigs, in leaf or twig lesions, and on infected, out-of-season fruit on the tree (Kiely 1948; Spósito et al. 2007, 2011; Wager 1952; Whiteside 1967).

Very little is known about the reproductive system of $P$. citricarpa based on genetic data. It was only recently that Wang et al. (2016) and Amorim et al. (2016) were able to clone the MAT genes, supporting the hypothesis that $P$. citricarpa is heterothallic. Mating type analyses of the global populations showed that both mating types were present in populations from Australia, Brazil, China, and South Africa at similar frequencies. This supports frequency-dependent selection of mating type and, hence, the occurrence of regular sexual reproduction in the life cycle of the pathogen. However, the association tests $\left(I_{A}\right.$ and $\left.\bar{r}_{d}\right)$ indicated significant linkage disequilibrium in clone-corrected populations, suggesting no or infrequent sexual reproduction in some of the populations (Queensland 1, Brazil, and China [Jiangxi]). The low genotype evenness, which indicates that only a few MLGs are present, in most of the South African populations and in the Brazilian population further indicates that these populations have frequent clonal reproduction. This finding is surprising considering that historical data from epidemiological studies have shown that pycnidiospores play a relatively minor role in the epidemiology compared with ascospores (Kiely 1948; Kotzé 1981; McOnie 1964b; Spósito et al. 2007, 2008, 2011; Wager 1952; Whiteside 1967). However, our findings as well as the recent identification of a single clonal genotype causing epidemics in Florida (Wang et al. 2016) (this study) suggest a more significant contribution of asexual reproduction to the epidemiology of the disease, as was concluded by Spósito et al. (2011) for areas with highly suitable climates.

The importance of asexual reproduction to disease development may be management and climate dependent. Management practices in citrus types (lemon) that are known to produce multiple crops, or where the fruit remain on the trees during fruit set of the next crop, may likely result in symptomatic fruit that can produce pycnidiospores that coincided with the young susceptible fruitlets. It was shown in Brazil

TABLE 8. Linkage disequilibrium analyses for 12 populations of Phyllosticta citricarpa from Australia, Brazil, China, South Africa, and the United States with corresponding significance level $(P \text { value })^{\mathrm{a}}$



a $\mathrm{NCC}=$ nonclone-corrected populations, $\mathrm{CC}=$ clone-corrected populations, MLGs = multilocus genotypes, eMLG = expected MLGs after rarefaction, $I_{A}=$ index of association, and $\bar{r}_{d}=$ standardized index of association.

${ }^{\mathrm{b}}$ Country, province, state or county. NSW $=$ New South Wales, EC $=$ Eastern Cape, KZN $=$ KwaZulu-Natal, LIM $=$ Limpopo, MP $=$ Mpumalanga, and $\mathrm{NW}=$ North West. 
that, under high rainfall conditions, and particularly under management practices with overlapping fruit set, pycnidiospores played an important role in disease spread within trees (Spósito et al. 2007, 2011). Our data indicate that asexual reproduction in some populations is more important than previously thought. In the future, a structured within-orchard sampling strategy will shed more light on the role of asexual reproduction and pycnidiospores within and between trees in orchards where both mating types occur.

Our study on the global population genetic structure of $P$. citricarpa provides novel and important insights into historical dissemination of the pathogen, the genetic structure of the global population, and the reproductive system of the pathogen. Information on the introduction pathways of $P$. citricarpa to date has been based on historical records of first reports and speculations. The historical records can be incorrect and misleading, especially because the pathogen can be present in a latent form (cryptic infection) for a long period of time (Kiely 1948; Kotzé 1981; Wager 1952). The source of the South African population could be from the Far East or Australia. We also identified either Australia or South Africa as a likely source of the Brazilian population. Australia or South Africa can also be the source of the U.S. population, although it cannot be ruled out that the United States' MLG remained unsampled elsewhere. Our study, however, does not provide a complete picture of the introduction pathways, because additional populations from other countries in Asia and from New Caledonia and New Guinea need to be analyzed to determine whether the Oceanian countries, China, or another country in Asia was the source population from which dispersal of the pathogen to other continents took place. Knowledge of the reproductive system of $P$. citricarpa has only been based on epidemiological studies, which concluded that sexual reproduction frequently occurs in this pathogen system (Kiely 1948; Kotzé 1981; McOnie 1965). Our data support the importance of a sexual reproductive system but further indicate that, in some populations, asexual (clonal) reproduction may also be important.

\section{ACKNOWLEDGMENTS}

This work was financially supported by Citrus Research International and The Technology and Human Resources for Industry Programme. We thank CenGen (Pty.) Ltd., and S. Langenhoven and A. Pretorius (Department of Plant Pathology, Stellenbosch University), for assistance in the laboratory and technical support; and S. Maduna and A. van der Merwe (Department of Genetics, Stellenbosch University) for assistance with analyses in $\mathrm{R}$.

\section{LITERATURE CITED}

Agapow, P.-M., and Burt, A. 2001. Indices of multilocus linkage disequilibrium. Mol. Ecol. Notes 1:101-102.

Allwright, W. J. 1957. South African Co-operative Citrus Exchange Limited. Electric Printing Works (Pty.) Ltd., Pretoria, South Africa.

Amorim, R., Savi, D. C., Ferreira-Maba, L., Aluizio, R., Goulin, E. H., Takita, M. A., Machado, M. A., and Glienke, C. 2016. MAT gene idiomorphs suggest a heterothallic sexual cycle in the citrus pathogen Phyllosticta citricarpa. Eur. J. Plant Pathol. 147:325-337.

AQSIQ. 2014. General Administration of Quality Supervision. Inspection and Quarantine of the People's Republic of China, Beijing.

Baayen, R. P., Bonants, P. J. M., Verkley, G., Carroll, G. C., van der Aa, H. A., de Weerdt, M., van Brouwershaven, I. R., Schutte, G. C., Maccheroni, W., Jr, de Blanco, G. C., and Azevedo, J. L. 2002. Nonpathogenic isolates of the citrus black spot fungus, Guignardia citricarpa, identified as a cosmopolitan endophyte of woody plants, Guignardia mangiferae (Phyllosticta capitalensis). Phytopathology 92:464-477.

Balloux, F., Lehmann, L., and de Meeûs, T. 2003. The population genetics of clonal and partially clonal diploids. Genetics 164:1635-1644.

Benson, A. H. 1895. Black spot of the orange. Agric. Gaz. N. S. W 6:249.

Blankenberg, D., Von Kuster, G., Coraor, N., Ananda, G., Lazarus, R., Mangan, M., Nekrutenko, A., and Taylor, J. 2010. Galaxy: A web-based genome analysis tool for experimentalists. Chapter 19, Unit 19.10.1-21 in: Current Protocols in Molecular Biology F. M. Ausubel, R. Brent, R. E. Kingston, D. Moore, J. G. Seidman, and K. Struhl, eds. John Wiley \& Sons, Hoboken, NJ.

Bruvo, R., Michiels, N. K., D'Sousa, T. G., and Schulenberg, H. 2004. A simple method for calculation of microsatellite genotypes irrespective of ploidy level. Mol. Ecol. 13:2101-2106.
Carbonell-Caballero, J., Alonso, R., Ibañez, V., Terol, J., Talon, M., and Dopazo, J. 2015. A phylogenetic analysis of 34 chloroplast genomes elucidates the relationships between wild and domestic species within the genus Citrus. Mol. Biol. Evol. 32:2015-2035.

Carstens, E., Le Roux, H. F., Van Rooyen, L., Coetzee, J., Wentzel, R., Laubscher, W., Dawood, D., Holtzhausen, M. A., Schutte, G. C., Fourie, P. H., and Hattingh, V. 2012. Citrus black spot does not occur in the Western Cape, Northern Cape and Free State provinces of South Africa. S. Afr. J. Sci. 108:56-61.

Csárdi, G., and Nepusz, T. 2006. The igraph software package for complex network research. InterJournal Complex Syst. Article 1695.

Dlugosch, K. M., and Parker, I. M. 2008. Founding events in species invasions: Genetic variation, adaptive evolution, and the role of multiple introductions. Mol. Ecol. 17:431-449.

Doidge, E. M. 1929. Some diseases of citrus prevalent in South Africa. S. Afr. J. Sci. 26:320-325.

Everett, K. R., and Rees-George, J. 2006. Reclassification of an isolate of Guignardia citricarpa from New Zealand as Guignardia mangiferae by sequence analysis. Plant Pathol. 55:194-199.

FAO. 2014. Intentional Standards for Phytosanitary Measures, Publ. No. 27. 2006. Diagnostic protocols for regulated pests. Intentional Standards for Phytosanitary Measures, Publ. No. 27: Annex 5. Phyllosticta citricarpa (McAlpine) Aa on fruit. Secretariat of the International Plant Protection, Food and Agriculture Organization of the United Nations, Rome.

Fisher, R. A., and Yates, F. 1963. Table IV in: Statistical Tables for Biological Agricultural and Medical Research, 6th ed. Oliver \& Boyd, Ltd., Edinburgh.

Fourie, P. H., Schutte, G. C., Serfontein, S., and Swart, S. H. 2013. Modelling the effect of temperature and wetness on Guignardia pseudothecium maturation and ascospore release in citrus orchards. Phytopathology 103:281-292.

Giardine, B., Riemer, C., Hardison, R. C., Burhans, R., Elnitski, L., Shah, P., Zhang, Y., Blankenberg, D., Albert, I., Taylor, J., Miller, W., Kent, W. J., and Nekrutenko, A. 2005. Galaxy: A platform for interactive large-scale genome analysis. Genome Res. 15:1451-1455.

Glienke, C., Pereira, O. L., Stringari, D., Fabris, J., Kava-Cordeiro, V., Galli-Terasawa, L., Cunnington, J., Shivas, R. G., Groenewald, J. Z., and Crous, P. W. 2011. Endophytic and pathogenic Phyllosticta species, with reference to those associated with citrus black spot. Persoonia 26:47-56.

Gmitter, F. G., and Hu, X. 1990. The possible role of Yunnan, China, in the origin of contemporary Citrus species (Rutaceae). Econ. Bot. 44:267-277.

Goecks, J., Nekrutenko, A., and Taylor, J. 2010. Galaxy: A comprehensive approach for supporting accessible, reproducible, and transparent computational research in the life sciences. Genome Biol. 11:R86.

Goodwin, S. B., Drenth, A., and Fry, W. E. 1992. Cloning and genetic analyses of two polymorphic, moderately repetitive nuclear DNAs from Phytophthora infestans. Curr. Genet. 22:107-115.

Grünwald, N. J., Goodwin, S. B., Milgroom, M. G., and Fry, W. E. 2003. Analysis of genotypic diversity data for populations of microorganisms. Phytopathology 93:738-746.

Hynniewta, M., Surendra Kumar Malik, S. K., and Rao, S. R. 2014. Genetic diversity and phylogenetic analysis of Citrus (L) from north-east India as revealed by meiosis, and molecular analysis of internal transcribed spacer region of rDNA. Meta Gene 2:237-251.

Jombart, T. 2008. adegenet: A R package for the multivariate analysis of genetic markers. Bioinformatics 24:1403-1405.

Kalinowski, S. T. 2005. HP-RARE 1.0: A computer program for performing rarefaction on measures of allelic richness. Mol. Ecol. Notes 5:187-189.

Kamvar, Z. N., Tabima, J. F., and Grünwald, N. J. 2014. Poppr: An R package for genetic analysis of populations with clonal, partially clonal, and/or sexual reproduction. PeerJ 2:e281.

Kiely, T. B. 1948. Preliminary studies on Guignardia citricarpa: The ascigerous stage of Phoma citricarpa McAlp. and its relation to black spot of citrus. Proc. Linn. Soc. N. S. W. 73:249-292.

Kotzé, J. M. 1981. Epidemiology and control of citrus black spot in South Africa. Plant Dis. 65:945-950.

Kotzé, J. M. 2000. Black spot. Pages 23-25 in: Compendium of Citrus Diseases. L. W. Timmer, S. M. Garnsey, and J. H. Graham, ed. American Phytopathological Society Press Inc., St. Paul, MN.

Lee, H. A. 1920. Black spot of citrus fruits caused by Phoma citricarpa. Philipp. J. Sci. 17:635-641.

Linde, C. C., Zala, M., and McDonald, B. A. 2009. Molecular evidence for recent founder populations and human-mediated migration in the barley scald pathogen Rhynchosporium secalis. Mol. Phylogenet. Evol. 51:454-464.

Liu, Y., Heying, E., and Tanumihardjo, S. A. 2012. History, global distribution, and neutral importance of citrus fruits. Compr. Rev. Food Sci. Food Saf. 11: 530-545.

Malik, S. K., Kumar, S., Singh, I. P., Dhariwal, O. P., and Chaudhury, R. 2013. Socio-economic importance, domestication trends and in situ conservation of wild Citrus species of Northeast India. Genet. Resour. Crop Evol. 60: 1655-1671. 
Marchionatto, J. B. 1928. Fitoparasitos de la Argentina nuevos o poco conocidos 11. Physis (Buenos Aires) 9:145.

McAlpine, D. 1899. Fungus Diseases of Citrus in Australia and Their Treatment. Agricultural Department, Melbourne, Australia.

McOnie, K. C. 1964a. Orchard development and discharge of ascospores of Guignardia citricarpa and the onset of infection in relation to the control of citrus black spot. Phytopathology 54:1448-1453.

McOnie, K. C. 1964b. Source of inoculum of Guignardia citricarpa, the citrus black spot pathogen. Phytopathology 54:64-67.

McOnie, K. C. 1965. Source of infection for black spot of citrus. S. Afr. Citrus J. 5:6-9.

Meyer, L., Sanders, G. M., Jacobs, R., and Korsten, L. 2006. A one day sensitive method to detect and distinguish between the citrus black spot pathogen Guignardia citricarpa and endophyte Guignardia mangiferae. Plant Dis. 90:97-101.

Miles, A. K., Tan, Y. P., Tan, M. K., Donovan, N. J., Ghalayin, A., and Drenth, A. 2013. Phyllosticta spp. on cultivated Citrus in Australia. Australas. Plant Pathol. 42:461-467.

Miles, A. K., Wyatt, P., Kopittke, R., Eelkema, M., Missenden, B., Hamacek, E., Shivas, M., and Drenth, A. 2008. Integrated disease management of citrus black spot (Guignardia citricarpa Kiely) in Queensland, Australia. Pages 1070-1076 in: 11th Int. Citrus Congress. X. Deng, J. Xu, S. Lin, and R. Guan, eds. China Agriculture Press, Wuhan, China.

Navarro de Andrade, E. 1933. Manual de citricultura. Parte I. Cultura e estatistica. Edicao de Charcaras e Quintaes, Sao Paulo, Brazil.

Nei, M. 1973. Analysis of gene diversity in subdivided populations. Proc. Natl. Acad. Sci. USA 70:3321-3323.

Paul, I., Van Jaarsveld, A. S., Korsten, L., and Hattingh, V. 2005. The potential global geographical distribution of citrus black spot caused by Guignardia citricarpa Kiely: Likelihood of disease establishment in the European Union. Crop Prot. 24:297-308.

Peakall, R., and Smouse, P. E. 2012. GenAlEx 6.5: Genetic analysis in Excel. Population genetic software for teaching and research-an update. Bioinformatics 28:2537-2539.

Peres, N. A., Harakava, R., Carroll, G. C., Adaskaveg, J. E., and Timmer, L. W. 2007. Comparison of molecular procedures for detection and identification of Guignardia citricarpa and G. mangiferae. Plant Dis. 91:525-531.

Powell, H. C. 1930. The culture of the orange and allied fruits. South African Agricultural Series Number 8. Central News Agency, Ltd., Johannesburg, South Africa.

R Core Team. 2013. R: A Language and Environment for Statistical Computing. Online publication. http://www.R-project.org/

Robbs, C. F., Pimentel, J. P., and Ribeiro, R. L. 1980. A mancha preta dos citros causada por Phoma citricarpa. Fitopatol. Bras. 5:455.

Rozen, S., and Skaletsky, H. J. 1998. Primer3. Online publication. http:// primer3.sourceforge.net/

Schubert, T. S., Dewdney, M. M., Peres, N. A., Palm, M. E., Jeyaprakash, A., Sutton, B., Mondal, S. N., Wang, N. Y., Rascoe, J., and Picton, D. D. 2012. First report of Guignardia citricarpa associated with citrus black spot on sweet orange (Citrus sinensis) in North America. Plant Dis. 96:1225.

Scora, R. W. 1975. On the history and origin of Citrus. Bull. Torrey Bot. Club 102:369-375.

Shannon, C. E., and Weaver, W. 1949. The Mathematical Theory of Communication. University of Illinois Press, Urbana.

Spósito, M. B., Amorim, L., Bassanezi, R. B., Bergamin Filho, A., and Hau, B. 2008. Spatial pattern of black spot incidence within citrus trees related to disease severity and pathogen dispersal. Plant Pathol. 57:103-108.
Spósito, M. B., Amorim, L., Bassanezi, R. B., Yamamoto, P., Felippe, M. R., and Czermainski, A. B. C. 2011. Relative importance of inoculum sources of Guignardia citricarpa on the citrus black spot epidemic in Brazil. Crop Prot. 30:1546-1552.

Spósito, M. B., Amorim, L., Ribeiro, P. J., Bassanezi, R. B., and Krainski, E. T. 2007. Spatial pattern of trees affected by black spot in citrus groves in Brazil. Plant Dis. 91:36-40.

Stringari, D., Glienke, C., de Christo, D., Maccheroni, W., Jr., and de Azevedo, J. L. 2009. High molecular diversity of the fungus Guignardia citricarpa and Guignardia mangiferae and new primers for the diagnosis of the citrus black spot. Braz. Arch. Biol. Technol. 52:1063-1073.

Wager, V. A. 1952. The black spot disease of citrus in South Africa. Sci. B. Dep. Agric. Union S. Afr. 303:1-52.

Wager, V.A. 1953. The black spot disease of citrus in South Africa. Citrus Grow. February:3-5

Wang, N.-Y., Rollins J. A., and Dewdney, M. M. 2013. Characterization of the mating-type locus (MAT) of Guignardia citricarpa, the fungal causal agent of citrus black spot. (Abstr.) Phytopathology 103:S2.156.

Wang, N.-Y., Zhang, K., Huguet-Tapia, J. C., Rollins, J. A., and Dewdney, M. M. 2016. Mating type and simple sequence repeat markers indicate a clonal population of Phyllosticta citricarpa in Florida. Phytopathology 106:1300-1310.

Wang, X., Chen, G., Huang, F., Zhang, J., Hyde, K. D., and Li, H. 2012. Phyllosticta species associated with citrus diseases in China. Fungal Divers. 52:209-224.

Whiteside, J. O. 1967. Sources of inoculum of the black spot fungus, Guignardia citricarpa in infected Rhodesian citrus orchards. Rhod. Zam. Mal. J. Agric. Res. 5:171-177.

Wickert, E., de Goes, A., de Souza, A., and de Macedo Lemos, E. G. 2012. Genetic diversity and population differentiation of the causal agent of citrus black spot in Brazil. Sci. World J. 2012:Article ID 368286. doi:10.1100/2012/ 368286

Wikee, S., Lombard, L., Crous, P. W., Nakashima, C., Motohashi, K., Chukeatirote, E., Alias, S. A., McKenzie, E. H., and Hyde, K. D. 2013a. Phyllosticta capitalensis. A widespread endophyte of plants. Fungal Divers. 60:91-105.

Wikee, S., Lombard, L., Nakashima, C., Motohashi, K., Chukeatirote, E., Cheewangkoon, R., McKenzie, E. H., Hyde, K. D., and Crous, P. W. 2013b. A phylogenetic re-evaluation of Phyllosticta (Botryosphaeriales). Stud. Mycol. 76:1-29.

Wulandari, N. F., To-anun, C., Hyde, K. D., Duong, L. M., de Gruyter, J., Meffert, J. P., Groenewald, J. Z., and Crous, P. W. 2009. Phyllosticta citriasiana sp. nov., the cause of citrus tan spot of Citrus maxima in Asia. Fungal Divers. 34:23-39.

Yeh, F. C., Yang, R., Boyle, T. J., Ye, Z. M., and Xiyan, J. 2000. POPGENE 32, Microsoft Windows-Based Freeware for Population Genetic Analysis. Molecular Biology and Biotechnology Centre, University of Alberta, Edmonton, AB Canada.

Yonow, T., Hattingh, V., and De Villiers, M. 2013. CLIMEX modelling of the potential global distribution of the citrus black spot disease caused by Guignardia citricarpa and the risk posed to Europe. Crop Prot. 44:18-28.

Zavala, M. G. M., Er, H. L., Goss, E. M., Wang, N. Y., Dewdney, M. M., and Van Bruggen, A. H. C. 2014. Genetic variation among Phyllosticta strains isolated from citrus in Florida that are pathogenic or nonpathogenic to citrus. Trop. Plant Pathol. 39:119-128.

Zhang, K., Wang, N. Y., Dewdney, M. M., and Rollins, A. 2015. Lonely peninsula: The mating-type and population of Phyllosticta citricarpa in Florida. (Abstr.) Phytopathology 105:S4.157. 